\title{
Photo-catalytic dye degradation of methyl orange using zirconia-zeolite nanoparticles
}

\author{
M MANSOURI ${ }^{1, *}$, N MOZAFARI $^{1}$, B BAYATI $^{1}$ and N SETARESHENAS ${ }^{2}$ \\ ${ }^{1}$ Department of Chemical Engineering, Ilam University, Ilam 69315-516, Iran \\ ${ }^{2}$ Department of Chemical Engineering, Eyvan-e-Gharb Branch, Islamic Azad University, Eyvan 694111-1359, Iran \\ *Author for correspondence (mansouri2010@yahoo.com; m.mansouri@ilam.ac.ir)
}

MS received 24 February 2019; accepted 17 May 2019

\begin{abstract}
In this research, the dye photo-catalytic removal was investigated using zirconia $\left(\mathrm{ZrO}_{2}\right)$ nanocatalysts, zeolite ( $\mathrm{Ze}), \mathrm{ZrO}_{2}-\mathrm{Ze}$ with different percentages and optimized $\mathrm{ZrO}_{2}-\mathrm{Ze}$ doped via urea, copper oxide and cerium oxide. In order to determine the optimal conditions, the effects of different catalysts and parameters such as dye concentration, UV lamp power, amount of the loaded catalyst and $\mathrm{pH}$ were investigated. The response surface methodology was used to obtain optimal experimental conditions. Physical and chemical properties of materials were investigated by X-ray diffraction, Fourier transform infrared, scanning electron microscopy and Brunauer-Emmett-Teller. Completely methyl orange (MO)dye removal (100\%) was achieved at optimal conditions under UV light during $80 \mathrm{~min}$. The optimal operational condition for $\mathrm{MO}$ photo-catalytic decomposition using an optimal $\mathrm{N}$-doped $10 \mathrm{wt} \% \mathrm{ZrO}_{2}$-zeolite nanocatalyst was obtained at UV lamp power, $\mathrm{pH}$, catalyst loading and dye concentration of $15 \mathrm{~W}, 3,0.4 \mathrm{~g}^{-1}$ and $5 \mathrm{mg}^{-1}$, respectively. Photo-catalytic degradation kinetics of MO described well using pseudo-first order which is in accordance with the Langmuir-Hinshelwood model $\left(k_{\text {app }}=0.031 \mathrm{~min}^{-1}\right)$.
\end{abstract}

Keywords. Advanced oxidation; N-doped zirconia-zeolite; experimental design; optimization; nanocatalyst.

\section{Introduction}

The photo-catalytic process has been successfully used to remove a wide range of pollutants such as dyes, phenols, surfactants, aromatic hydrocarbons and pesticides. The process is based on the production of highly active species (i.e., hydroxyl radicals) that have high oxidizing ability with dye molecules. This act causes decomposition of dyes and removal from water and wastewaters [1]. Due to high optical, electrical and catalytic properties, titania and zirconia nano-photocatalysts have a great potential to be considered as catalysts for water and wastewater treatment $[1,2]$. Recently, zirconia has been attracted more attention among the photocatalysts due to its biological and chemical ineffectiveness, lack of toxicity, good environmental stability at aqueous solution and safe applications [2]. In the literature reported that $\mathrm{ZrO}_{2}$ structural changing, porosity controlling and crystallization developing are effective factors to increase the removal capacity of pollutants [3].

Low adsorption and surface area are the most important limitations for photocatalyst efficiency. Therefore, the stabilization of semiconductors on suitable supports can overcome these limitations with an increase in the separation of charges, an increase in the lifespan of the charge carriers, an increase in charge surface transfer to adsorbent substrates and the reduction of cost. Zeolites are suitable supports for this work due to its three-dimensional crystalline structure, high-physical and chemical resistance, uniform holes and channels, high surface areas, excellent adsorption capacity and unique structures. Among the zeolites, synthesized zeolites have more advantages than natural zeolites because they are synthesized with a pure phase and uniformity. In addition, the synthesized zeolites can be produced with a wide range of pore sizes [4-6]. The removal of various compounds including Reactive Black-5 [4], Brown-NG [5] and methyl orange (MO) [6] by titanium dioxide stabilized on the surface of zeolites has been performed in several studies. The results of these studies show the efficiency and degradation rate (about 98\%) of this photocatalyst compared with the use of pure titanium dioxide as a catalyst. In the study presented by Bhattacharjee et al, the photo-catalytic degradation of Reactive Black-5 dye was investigated using a $\mathrm{TiO}_{2}$ photocatalyst under UV radiation from aqueous solution. They investigated the effect of UV irradiation and $\mathrm{pH}$ of solution on the dye removal, and reported the dye removal of 94 and $75 \%$ at $\mathrm{pH}$ of 6.4 and 4.8, respectively [7]. The results of Panpa et al on methylene blue photocatalytic degradation using a $\mathrm{TiO}_{2} @ \mathrm{ZSM} 5$ photocatalyst showed that the dye removal using this photocatalyst at $2.5 \mathrm{~h}$ was higher than that for pure $\mathrm{TiO}_{2}$ which leads to complete dye removal [8].

Zhao et al synthesized $\mathrm{ZnO}$ nanotubes using a coating method and obtained the nanotubes with a length distribution of $25 \mu \mathrm{m}$, an internal diameter of $80 \mathrm{~nm}$ and a thickness of $35 \mathrm{~nm}$. They observed that $97.6 \%$ of the MO dye (soluble 
in water) could remove over a period of $8 \mathrm{~h}$ at a pH of 13 [9]. Ismail et al synthesized nanotubes of zirconia and tested their photo-catalytic ability. They found $30 \%$ of MO removal in the presence of $\mathrm{ZrO}_{2}$ nanotubes after 120 min under ultraviolet light [10].

Basahel et al investigated the effect of the crystalline structure of $\mathrm{ZrO}_{2}$ nanoparticles on the photocatalytic decomposition of MO. They synthesized triangular, tetrahedral and monoclinic phases of $\mathrm{ZrO}_{2}$ porous nanoparticles with different methods and measured the photocatalytic performance of three- $\mathrm{ZrO}_{2}$ samples for the decomposition of MO. They showed that, under optimal operating conditions, the $\mathrm{m}-\mathrm{ZrO}_{2}$ sample (monoclinic) had more decomposition for $\mathrm{MO}$ compared to $\mathrm{t}-\mathrm{ZrO}_{2}$ (tetrahedral) and $\mathrm{c}-\mathrm{ZrO}_{2}$ (cubic) samples. The catalytic activity specified for the $\mathrm{m}-\mathrm{ZrO}_{2}$ sample catalyst was strongly influenced by the effects of factors such as the presence of a small amount of the zirconium dioxide phase, crystallinity, pore size distribution and high density of hydroxyl groups in the surface [11].

The effect of the doping of semiconductors has also been studied in the research. Yoa et al examined the photocatalytic decomposition of the MO dye using lanthanum (nanomagnets)-doped-titanium dioxide nanocatalysts. The nanoparticles were synthesized by the sol-gel method, and dye decomposition was reported as $85 \%$ in an optimum molar percentage of 0.15 [12]. Mzoughi et al studied the photocatalytic activity of removing Eosin $\mathrm{Y}$ dye in aqueous solution under sunlight by synthesized zirconium dioxide and $\mathrm{Nd}-$ $\mathrm{ZrO}_{2}-\mathrm{G}$. It was observed that the $\mathrm{Nd}-\mathrm{ZrO}_{2}-\mathrm{G}$ catalyst has the potential to degrade the dye compared to the zirconium dioxide. Using a $0.3 \mathrm{wt} \% \mathrm{Nd}-\mathrm{ZrO}_{2}-\mathrm{G}$ catalyst, $80 \%$ dye removal was performed in $180 \mathrm{~min}$ [13].

As earlier studies have shown, the stabilized zirconium dioxide on the zeolite surfaces has not yet been studied in the research. Therefore, the aim of the present study is to synthesize a photocatalyst with zeolite content and coated with $\mathrm{ZrO}_{2}$ nanoparticles, which are doped by metals such as cerium oxide, copper oxide and non-metallic such as urea. Further, the physical and chemical properties of the photo-catalyst were investigated by various characterization techniques. Also, the photo-catalytic properties of the product were tested to remove MO dye under UV light. In order to determine the optimal conditions for high-performance dye removal, the effect of operational parameters on the photocatalytic degradation, including $\mathrm{pH}$, dye concentration, lamp power and amount of loaded photocatalyst was investigated under UV light.

\section{Methods}

\subsection{Materials}

Zirconium(IV) propoxide $\left(\mathrm{Zr}\left[\mathrm{O}\left(\mathrm{CH}_{2}\right)_{2} \mathrm{CH}_{3}\right]_{4}\right)$, copper nitrate $\left(\mathrm{Cu}\left(\mathrm{NO}_{3}\right)_{2} 6 \mathrm{H}_{2} \mathrm{O}\right)$, cerium nitrate $\left(\mathrm{Ce}\left(\mathrm{NO}_{3}\right)_{3} 6 \mathrm{H}_{2} \mathrm{O}\right)$, urea $\left(\mathrm{NH}_{2} \mathrm{CONH}_{2}\right)$ materials, sodium hydroxide $(\mathrm{NaOH})$, sodium aluminate $\left(\mathrm{AlNaO}_{2}\right)$, acetic acid $\left(\mathrm{CH}_{3} \mathrm{COOH}\right)$, isopropanol $\left(\mathrm{C}_{3} \mathrm{H}_{7} \mathrm{OH}\right)$ and nitric acid $\left(\mathrm{HNO}_{3}\right)$ were all of analytical grade, purchased from Aldrich, USA, and used without further purification. Also, tetraethyl orthosilicate (TEOS, $\left.\mathrm{C}_{8} \mathrm{H}_{20} \mathrm{O}_{4} \mathrm{Si}\right)$ and $\mathrm{MO}\left(\mathrm{C}_{14} \mathrm{H}_{14} \mathrm{~N}_{3} \mathrm{NaO}_{3} \mathrm{~S}\right)$ were purchased from Merck, Germany.

\subsection{Instruments}

The X-ray diffraction (XRD) patterns of the prepared materials were recorded on an X-ray diffractometer (Siemens D5000) using Ni filtered $\mathrm{CuK} \alpha$ radiation from $2 \theta=2-80^{\circ}$. The crystalline size of nanoparticles is computed using obtained information from XRD and the Scherrer equation. A scanning electron microscope (SEM, Leo 1455 VP) was used for the identification of nanoparticle surface morphological features. A UV-Vis spectrophotometer (Model $\mathrm{T}^{+} 0^{+}$, PG Instruments, UK) was used for measuring the amount of residual MO. A TRB-5 quartz capillary column of $30 \mathrm{~m} \times 0.53 \mathrm{~mm}$ with a $3 \mu \mathrm{m}$ film thickness was used in a UV-Vis spectrophotometer. To analyse the chemical structure of samples, Fourier transform infrared (FTIR) spectroscopy absorption spectra for all samples were recorded in the range of $400-4000 \mathrm{~cm}^{-1}$ with a 460 Plus Jasco spectrophotometer (USA) using $\mathrm{KBr}$ pellets at room temperature. Each sample was recorded with 32 scans at an effective resolution of $4 \mathrm{~cm}^{-1}$. The specific surface area of each sample was calculated by using the Brunauer-Emmett-Teller (BET) method (UPA-150, Microtrac).

\subsection{Nanoparticle synthesis}

In this research, the $\mathrm{ZrO}_{2}$ nanocatalysts, zeolite and $\mathrm{ZrO}_{2}-$ Ze nanocatalysts with different percentages and optimized $\mathrm{ZrO}_{2}-\mathrm{Ze}$ doped via urea, copper oxide and cerium oxide were used for MO photocatalytic removal. The methods for their synthesis are as follows.

\subsection{Synthesis of zeolite-NaX}

The used zeolite in this study is $\mathrm{NaX}$ type which is synthesized as follows. Firstly, $49.14 \mathrm{ml}$ of distilled water was added into a $100 \mathrm{ml}$ beaker, then $4.37 \mathrm{~g}$ of sodium hydroxide and $3.06 \mathrm{~g}$ of sodium aluminate were added to the solution. The solution was agitated until well dissolved. In this case, the temperature of the solution is raised, hence it is placed in a cold water bath until temperature reaches to an ambient level. Then, $7.93 \mathrm{ml}$ of TEOS was poured into the burette, added dropwise to the solution and stirred for $40 \mathrm{~min}$. The solution was transferred to an autoclave and placed in an oven at $90^{\circ} \mathrm{C}$ for $15 \mathrm{~h}$. After this period, the solution was filtered and the attained precipitate was mixed with a large amount of distilled water and agitated for $1 \mathrm{~h}$. This solution was aged for one day to precipitate. The precipitate was washed until to achieve natural $\mathrm{pH}$ and finally dried in an oven at $100^{\circ} \mathrm{C}$ for $24 \mathrm{~h}$. 


\subsection{Zirconia nanoparticle synthesis}

The $\mathrm{ZrO}_{2}$ nanoparticles were synthesized by the sol-gel method. Firstly, the solution containing zirconium(IV) propoxide is added to isopropanol with a molar ratio of $1 \mathrm{Zr}: 15$ isopropanol. After the solution becomes completely uniform, dilute nitric acid is added slowly to it using the burette. The total solution was kept at $30^{\circ} \mathrm{C}$ and stirred by the magnet for $50 \mathrm{~min}$ (when the total nitric acid was added to the solution). The added nitric acid reacted with an alcohol which causes the decomposition of $\mathrm{H}_{2} \mathrm{O}$ and creates the catalytic properties. The molar ratio of solution compounds was $1.0 \mathrm{H}_{2} \mathrm{O}: 0.6$ $\mathrm{HNO}_{3}: 7.5$ isopropanol. After the solution being completely uniform, it was agitated for $2 \mathrm{~h}$ until the gel was prepared. The $\mathrm{pH}$ was increased from 2 to 3 over the duration of the gel creation. The resulting mixture was then dried at $120^{\circ} \mathrm{C}$ for $12 \mathrm{~h}$. After drying, the catalyst precursor was calcined using an electrical furnace at $600^{\circ} \mathrm{C}$ under an air atmosphere for $6 \mathrm{~h}$.

\subsection{Synthesis of doped zirconia-zeolite nanoparticles}

The zirconia with various weight ratios of $10,30,50$ and $70 \%$ was used to achieve the optimum value for the zirconia-zeolite catalyst. After zeolite synthesis, it was weighed to the required amount and added to the solution containing zirconium(IV) propoxide and isopropanol with a specified ratio. The continuation of the synthesis process is similar to the synthesis of zirconia nanocatalysts. The synthesis of the zirconia-zeolite catalyst doped by $0.3 \mathrm{~mol}$ of various promoters (urea, copper oxide and cerium oxide) is similar to the above mentioned procedure.

\subsection{MO photocatalytic decomposition procedure}

The photo-catalytic decomposition of MO was carried out by a cylindrical Pyrex reactor with a length of $460 \mathrm{~mm}$ and a volume of 11 . The reactor has a valve for sampling during the process, and the contents are exposed to a UVC-lamp with varying powers of 4,8 and $15 \mathrm{~W}$. The solution in the reactor circulates in a closed cycle between the tank of a pump and the reactor inside. The SOBO aquarium pump with a power of $15 \mathrm{~W}$ and a flow rate of $21 \mathrm{~min}^{-1}$ was used to flow inside the reactor. The investigated parameters in the process include the UV lamp power, the amount of catalyst (catalyst dosage), dye concentration and $\mathrm{pH}$. To determine the adsorbance of the synthesized catalysts, the solution was poured into the reactor, and the pump was switched on for $30 \mathrm{~min}$ in the dark mode to bring about adsorption on the surface of the nanocatalysts. The solution was then exposed to UV light for $80 \mathrm{~min}$; the amount removed was measured using a UV instrument at different times (at a wavelength of $508 \mathrm{~nm}$ ). The percentage of dye removal was also calculated by using the following equation:

$$
X=\frac{C_{0}-C}{C_{0}} \times 100,
$$

where $C_{0}$ and $C$ are the initial and final concentrations, respectively. To avoid any error, tests were repeated at three times. The standard error (SE) of the data is also calculated by dividing standard deviation (SD) by the number of repeated experiments in accordance with the following

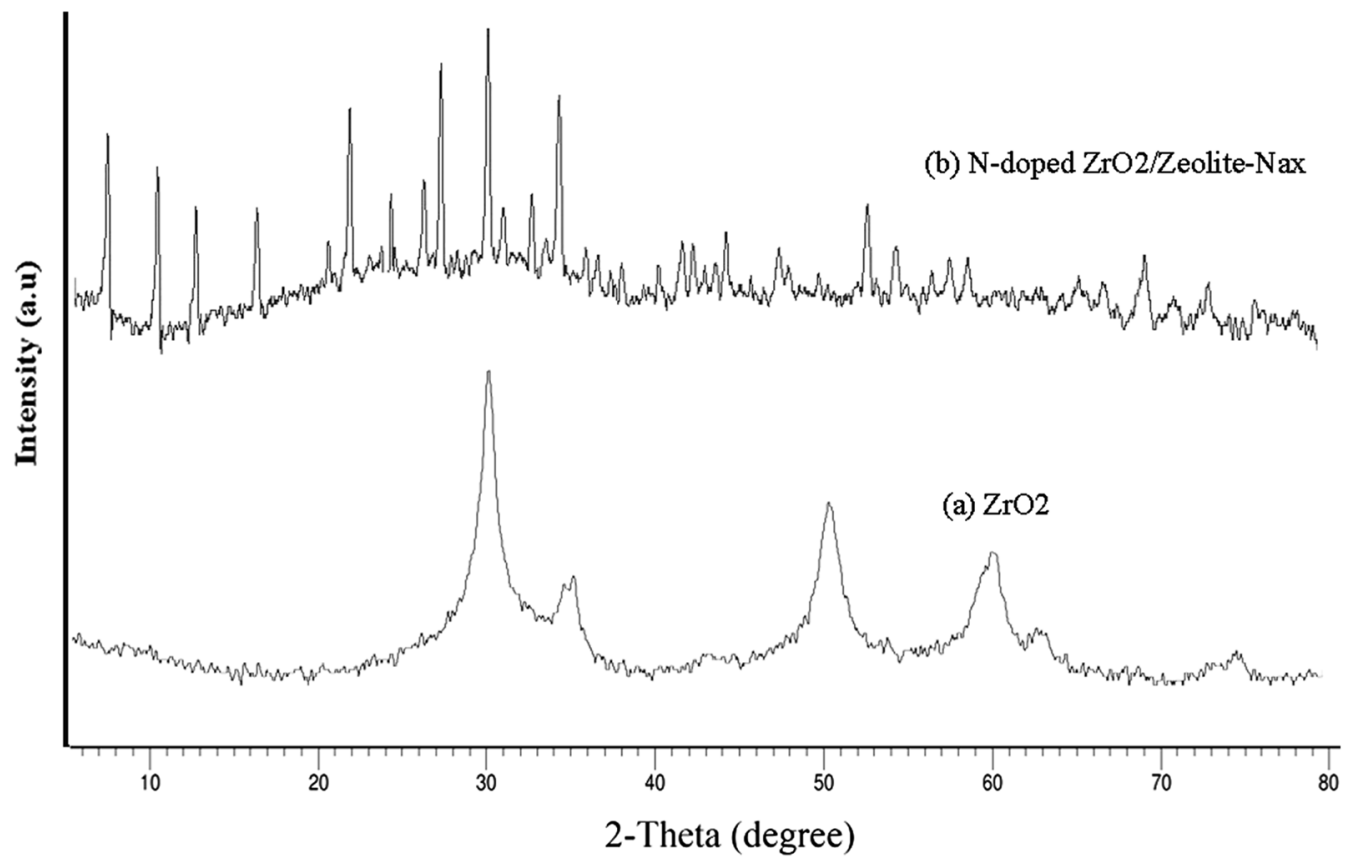

Figure 1. XRD patterns of (a) $\mathrm{ZrO}_{2}$ and (b) $\mathrm{N}$-doped $\mathrm{ZrO}_{2}$-zeolite-NaX. 
equation:

$$
\begin{aligned}
\mathrm{SE} & =\frac{\mathrm{SD}}{\sqrt{N}}, \\
\mathrm{SD} & =\sqrt{\frac{\sum(X-\bar{X})^{2}}{N-1}},
\end{aligned}
$$

where $N$ is the number of repetitions. $X$ and $\bar{X}$ are the percentage of colour removal at each test and at the mean of repetitions, respectively.

\section{Results and discussion}

\subsection{Characterization of nanoparticles}

XRD was used to determine the crystalline structure of synthesized zeolite-NaX, $\mathrm{ZrO}_{2}$ nanoparticles and $\mathrm{N}$-doped $\mathrm{ZrO}_{2}-\mathrm{Ze}$, and results are shown in figure 1 . The $\mathrm{X}$-ray $2 \theta$ diffraction lines show the existence of two nanocrystals for zirconia (figure 1a), the monoclinic phase at $2 \theta=$ $30.47,36.78,50.17$ and 63.81 according to JCPDS 37-1484 and the tetragonal phase at $2 \theta=35.19,47.67,59.16$ and 74.69 according to JCPDS 80-0965. Also, the peaks/lines that indicate impurities in the material are not seen in this pattern. The obtained XRD pattern for $\mathrm{N}$-doped $\mathrm{ZrO}_{2}-\mathrm{Ze}$ is shown in figure $1 \mathrm{~b}$. The sharp peaks in the $2 \theta$ ranges of $3-35^{\circ}$ indicate that the structure of zeolite is well crystallized. The NaX phase was identified on the basis of a group of characteristics of their reflections $\left(d_{\mathrm{hkl}}=\right.$ 7.54, 10.55, 12.94, 16.47, 27.42 and 52.73). The detailed JCPDS pattern lines for zeolite-NaX are already mentioned in the literature [7]. The zirconia peaks are distinctly seen in both $\mathrm{ZrO}_{2}$ and $\mathrm{N}$-doped $\mathrm{ZrO}_{2}-\mathrm{Ze}-\mathrm{NaX}$. The XRD pattern given in figure confirms the presence of urea through peaks at $2 \theta=22.20,47.16$ and $73.13^{\circ}$. This shows the formation of urea and $\mathrm{ZrO}_{2}$ nanoparticles over the formed zeolite framework. The average crystallite sizes of the photocatalysts are: $\mathrm{ZrO}_{2}=7.13 \mathrm{~nm}$ and $\mathrm{N}$-doped $\mathrm{ZrO}_{2}$ /zeolite- $\mathrm{NaX}=$ $40.80 \mathrm{~nm}$. Therefore the formed $\mathrm{ZrO}_{2}$ is in a crystallite and nano-form.

FTIR spectroscopy is used to determine the functional groups in zeolite- $\mathrm{NaX}, \mathrm{ZrO}_{2}$ and urea, and it is also used to prove the presence of these materials in the final synthesized nanoparticles. Figure $2 \mathrm{a}-\mathrm{c}$ shows the FTIR analysis results for the synthesized nanoparticles of zeolite-NaX, synthesized $\mathrm{ZrO}_{2}$ nanoparticles and pure urea, respectively. Also, in figure $2 \mathrm{~d}$, the transmission spectra of N-doped $10 \mathrm{wt} \%$ $\mathrm{ZrO}_{2}$-zeolite nanoparticles are presented. Figure $2 \mathrm{a}$ shows the IR spectrum of the synthesized zeolite-NaX nanoparticles; the highest peak intensity appeared at $980 \mathrm{~cm}^{-1}$ indicates the asymmetric stretching vibration of $\mathrm{Si}-\mathrm{O}-\mathrm{Al}$ in the zeolite framework. The absorption band in the range of 980 to $1320 \mathrm{~cm}^{-1}$ shows the presence of substitutional $\mathrm{Al}$ atoms in tetragonal forms in the silica structure, which

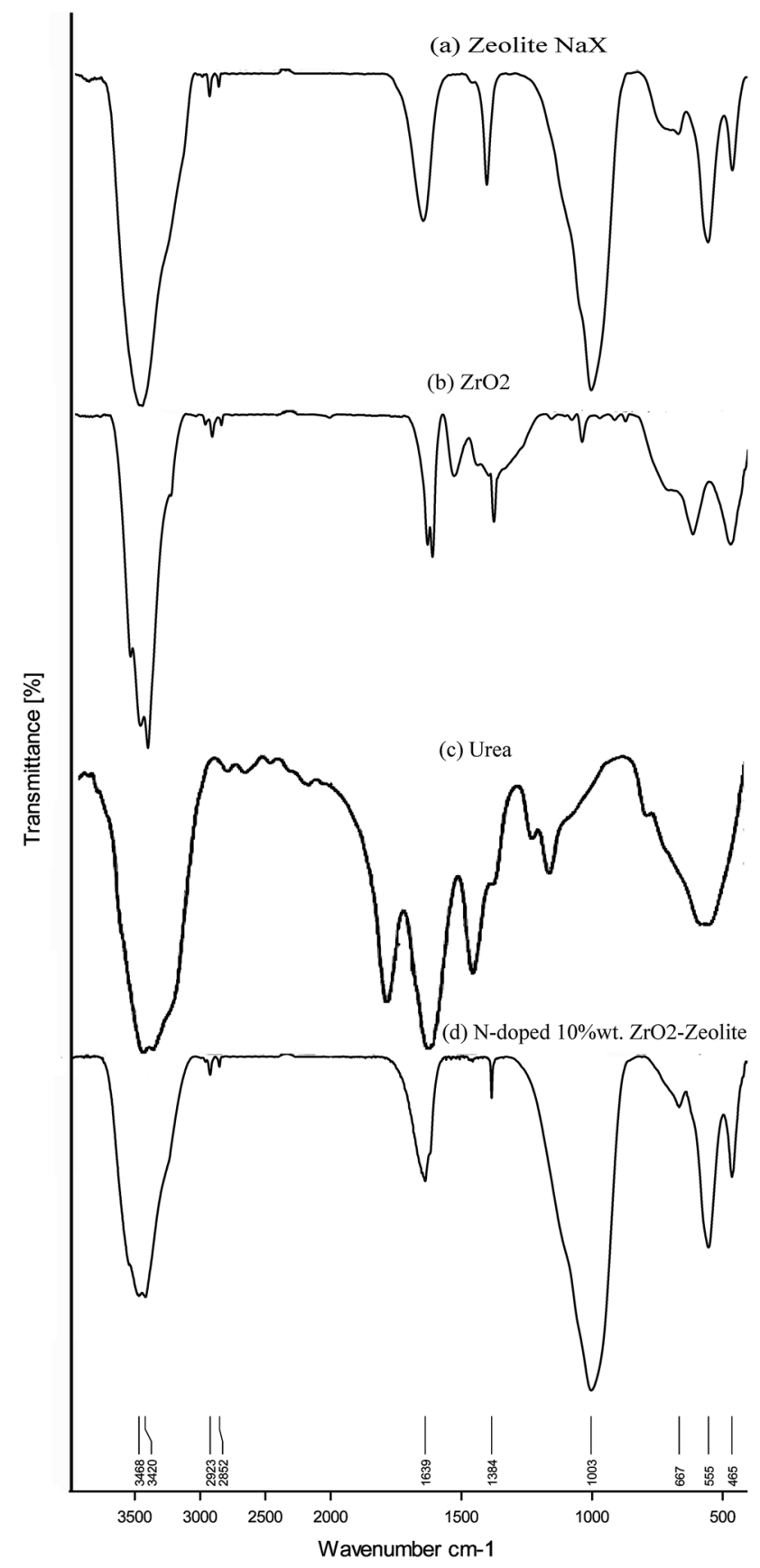

Figure 2. FTIR spectra of (a) zeolite-NaX, (b) $\mathrm{ZrO}_{2}$, (c) urea and (d) $\mathrm{N}$-doped $\mathrm{ZrO}_{2}$-zeolite-NaX.

characterizes the formation of zeolite. Also, the observed absorption band at a wavelength of $3470 \mathrm{~cm}^{-1}$ is related to the stretching vibration of the $\mathrm{O}-\mathrm{H}$ functional group. The peak obtained at a wavelength of $1646 \mathrm{~cm}^{-1}$ shows the bending state of water molecules. All of these observed specifications confirm the formation of zeolite ( $\mathrm{Ze}-\mathrm{NaX})$ [14]. In the IR spectrum of the synthesized zirconia nanoparticles (figure 2b), the observed peaks at 3472 and $1639 \mathrm{~cm}^{-1}$ are assigned to the structural vibrations of physically adsorbed $-\mathrm{OH}$ groups connected with $\mathrm{Zr}^{4+}$ and to scissor bending 
mode of coordinated molecular water, respectively [15]. The band at $1384 \mathrm{~cm}^{-1}$ is assigned to the adsorption of non-bridging $\mathrm{OH}$ groups. Also, the appeared peak at a wavelength of $1429 \mathrm{~cm}^{-1}$ is corresponding to the absorption of the $\mathrm{O}-\mathrm{H}$ functional group. The peak observed at a wavelength of $1049 \mathrm{~cm}^{-1}$ can be attributed to one of the zirconyl groups [15].

The absorption bands obtained at 521 and $438 \mathrm{~cm}^{-1}$ are related to the monoclinic structure of zirconium $\left(\mathrm{m}-\mathrm{ZrO}_{2}\right)$, and a sharp peak appeared at a wavelength of $625 \mathrm{~cm}^{-1}$ corresponds to the $\mathrm{Zr}-\mathrm{O}$ vibrations, associated with the tetragonal structure of $\mathrm{ZrO}_{2}\left(\mathrm{t}-\mathrm{ZrO}_{2}\right)$, which also matches with the XRD results [16]. The urea IR analysis shows a peak at $1667 \mathrm{~cm}^{-1}$ which is attributed to the stretching frequency of $\mathrm{C}=\mathrm{O}$ bonding. Also, the stretching and deformation frequencies of $\mathrm{N}-\mathrm{H}$ bonds have been obtained in the wavelength range of 3455 and $1625 \mathrm{~cm}^{-1}$, respectively. The stretching frequency of $\mathrm{C}-\mathrm{N}$ has appeared at a wavelength of $1453 \mathrm{~cm}^{-1}$ [17]. By comparing figure $2 \mathrm{a}-\mathrm{c}$ with figure $2 \mathrm{~d}$, it is evident that the occurred variations in the peak intensities of $667,1384,1639$ and $3468 \mathrm{~cm}^{-1}$ are due to the presence of $\mathrm{ZrO}_{2}$ and urea in nanoparticles of $\mathrm{N}$-doped $10 \mathrm{wt} \% \mathrm{ZrO}_{2}-$ zeolite.

The morphological surface and size of nanoparticles were investigated by SEM. Images obtained from $\mathrm{ZrO}_{2}$ nanoparticles and synthesized $\mathrm{N}$-doped $\mathrm{ZrO}_{2}-\mathrm{Ze}$ are shown in figure 3. As shown in figure 3a, the $\mathrm{ZrO}_{2}$ nanoparticles have been adhered together due to the high activity of the surface-to-volume ratio. This phenomenon is also called agglomeration. The aforementioned image confirms the spherical and almost uniform structure with a size of $\sim 40 \mathrm{~nm}$ for nanoparticles. Regarding the obtained SEM image for $\mathrm{N}$-doped $\mathrm{ZrO}_{2}-\mathrm{Ze}$ photo-catalyst (figure $3 \mathrm{~b}$ ), it can be observed that the $\mathrm{ZrO}_{2}$ particles are uniformly distributed at the surface of zeolite; these particles have nanometre dimensions less than $45 \mathrm{~nm}$. This is due to the successful stabilization of nanoparticles on the zeolite-NaX substrate. From the morphological aspect, the sample contains cubic zeolite and has a relatively uniform size $<100 \mathrm{~nm}$.

The textural properties, including the specific surface area, total pore volume and mean pore diameter derived from the $\mathrm{N}_{2}$ adsorption-desorption isotherms and pore size distributions of all binary oxides are summarized in table 1 .

Table 1 shows that the specific surface area of the $10 \mathrm{wt} \%$ $\mathrm{ZrO}_{2}$-zeolite catalyst is less than the pure zeolite-NaX as a result of introducing $\mathrm{ZrO}_{2}$. An increase in the $\mathrm{ZrO}_{2}$ content decreases the specific surface area due to an increase in the crystal size and the pore blockage of the support. As compared to $10 \mathrm{wt} \% \mathrm{ZrO}_{2}$-zeolite, N-doped $10 \mathrm{wt} \%$ $\mathrm{ZrO}_{2}$-zeolite has a higher specific surface area and higher pore volume, but lower average pore diameter. The increased specific surface area after N-doping is probably due to the decreased crystalline size or the formation of more pores with smaller sizes as a result of gas liberation during the decomposition of the zirconium hydroxide-urea complex in the calcination process. It is clearly seen that N-doping has beneficially altered the textural properties of $10 \mathrm{wt} \% \mathrm{ZrO}_{2}-$ zeolite.

\subsection{Photocatalytic process in the presence and absence of light}

The dye degradation efficiency $v s$. time by the dye adsorption of the zirconia nanocatalyst in the absence of UV light, and direct photolysis by UV light without the presence of the catalyst is shown in figure 4 . The MO dye sample with a concentration of $10 \mathrm{mg} \mathrm{l}^{-1}$, the initial $\mathrm{pH}$ of solution and a lamp power of $15 \mathrm{~W}$ for $80 \mathrm{~min}$ in the absence of a catalyst was kept under UV light without any additive and oxidation. The results obtained after 80 min showed that this dye is removed by about $9 \%$ without the photocatalyst and under UV light radiation, and that it has a high stability.

The low-decomposition percentage of MO dye in the reference sample is due to the main role of UV light radiation to produce very active hydroxyl radicals. Devi and Rajashekhar [18] and Xin et al [19] obtained similar results, dye removal less than $10 \%$ by just UV irradiation, in their studies. When the $\mathrm{ZrO}_{2}$ photocatalyst was used alone at $0.1 \mathrm{~g} \mathrm{l}^{-1}$, the efficiency of MO dye removing was lower and was found to be about $4 \%$. This shows that the production of hydroxyl radicals, which requires catalysts for the formation, plays a major role in the beginning of dye decomposition. This also proves that the most important factor in initiating and accelerating the photochemical reaction is the simultaneous presence of a catalyst and UV radiation [20], which are discussed below.

\subsection{Photocatalytic activity of various catalysts}

In this work, photocatalytic removal of MO-organic dye by nanophoto-catalysts of $\mathrm{ZrO}_{2}$, zeolite, $\mathrm{ZrO}_{2}-\mathrm{Ze}$ with different weight percentages and optimized $\mathrm{ZrO}_{2}-\mathrm{Ze}$ doped with various promoters (nitrogen, copper oxide and cerium oxide) was investigated. This investigation was carried out under operational conditions of initial $\mathrm{pH}$ of solution, lamp power of $15 \mathrm{~W}$, photo-catalyst concentration of $0.1 \mathrm{~g} \mathrm{l}^{-1}$ and $10 \mathrm{mg} \mathrm{l}^{-1}$ of MO dye.

\subsection{Zeolite and pure zirconia catalysts}

The MO photocatalytic degradation using catalysts of zeolite and pure $\mathrm{ZrO}_{2}$ has been presented in figure 5. The dashed line indicates the beginning of UV irradiation. The results show that the adsorption value for zeolite (about $7 \%$ ) is more than that for $\mathrm{ZrO}_{2}$ (about 4\%) in the initial half-hour for the tests which carried out in the dark; this is probably due to the higher surface area of its specific surface. After $80 \mathrm{~min}$ of exposure under UV light, the dye removal percentage for zirconia was achieved by about $37 \%$ which is more than that for zeolite (about 30\%). The removal rate graph for zeolite, when the equilibrium state was achieved, shows that the MO removal by zeolite was derived from adsorption and photocatalytic processes. 

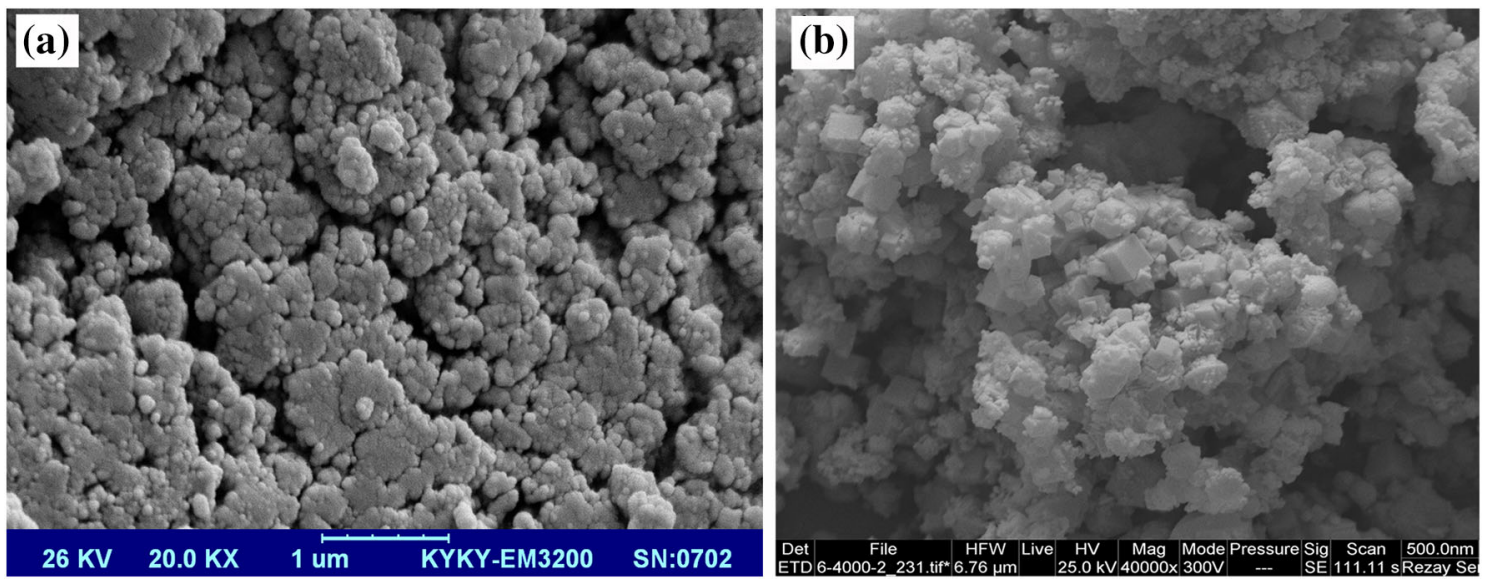

Figure 3. SEM images of (a) $\mathrm{ZrO}_{2}$ and (b) $\mathrm{N}$-doped $\mathrm{ZrO}_{2}-$ zeolite-NaX.

Table 1. Textural properties of the prepared materials.

\begin{tabular}{lccc}
\hline Sample & Surface area $\left(\mathrm{m}^{2} \mathrm{~g}^{-1}\right)$ & Pore volume $\left(\mathrm{cm}^{3} \mathrm{~g}^{-1}\right)$ & Average pore diameter $(\mathrm{nm})$ \\
\hline $\mathrm{ZrO}_{2}$ & 76.31 & 0.09 & 3.51 \\
$\mathrm{Zeolite}-\mathrm{NaX}$ & 369.5 & 0.12 & 1.02 \\
$10 \mathrm{wt} \% \mathrm{ZrO}_{2}$-zeolite & 323.5 & 0.11 & 2.39 \\
$\mathrm{~N}$-doped 10 wt\% $\mathrm{ZrO}_{2}$-zeolite & 356.8 & 0.12 & 1.21 \\
\hline
\end{tabular}

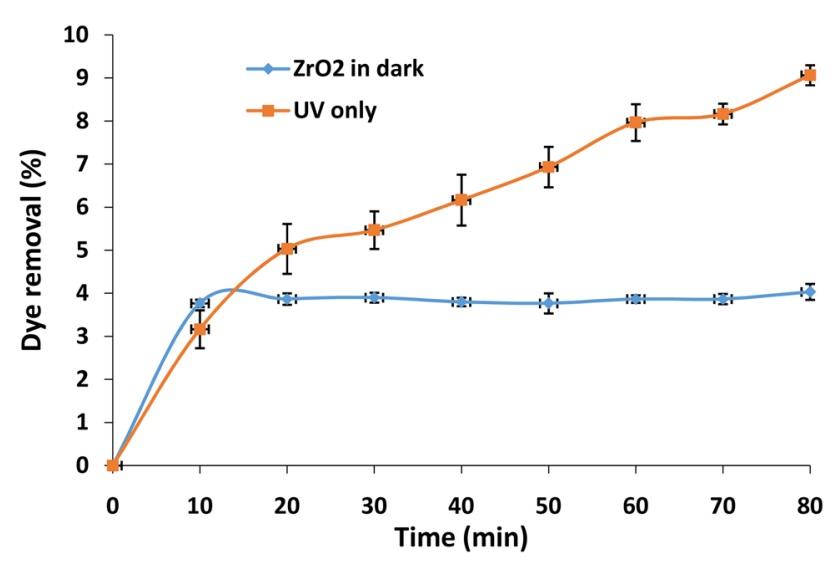

Figure 4. Effect of UV light and $\mathrm{ZrO}_{2}$ nanoparticles on MO degradation.

As is known, zirconia photocatalytic activity is higher than zeolite which is due to the lower band gap energy of zirconia. The most important limitation for photocatalyst performance is the low adsorption and surface area. Thus, the zirconia stabilization on the adsorbent increases the efficiency and photodecay due to the adsorption of organic molecules and the increase in the organic concentration around the catalyst particles. Stabilization on the surface of an absorbent facilitates the separation of the catalyst from the dye, reducing its wasting and resulting in better removal of organic pollutants.
Among the various supports that have been investigated for semiconductor stabilization, zeolites are recognized as the best support due to their porous structure, pore size, regular and uniform pores, high adsorption capacity, environmentally friendly and structural photodecay stability (photochemical stability) [5,6].

\subsection{Combination of zeolite-zirconia catalysts}

The MO photo-catalytic decomposition by a combination of $\mathrm{ZrO}_{2}$-zeolite catalysts is presented in figure 5. On comparing the zeolite, $\mathrm{ZrO}_{2}$ addition causes an increase in dye removal. By comparing photo-catalytic removal efficiency of fourdifferent ratios of $\mathrm{ZrO}_{2}-\mathrm{Ze}$ catalysts, the sample with $10 \mathrm{wt} \%$ of $\mathrm{ZrO}_{2}$ to zeolite had the highest removal rate. The results for $10 \mathrm{wt} \% \mathrm{ZrO}_{2}$-zeolite showed that the UV-degradation efficiency has varied from about 30 to $40 \%$ relative to pure zeolite in $80 \mathrm{~min}$. The addition of $\mathrm{Zr}$ ions provides a large surface charge which acts as an electrical force and increases the efficiency of the separation of the electron-hole pair. Zr ions, also as electronic traps, reduce the surface recombination rate, which maintains the activity of hydroxyl radicals for a long period. In the higher ratios of $\mathrm{ZrO}_{2}$, the mobility of carrier charges decreases, which increases the surface recombination rate and, as a result, shortens the life of hydroxyl radicals [2]. The other reason for lowering the dye removal by increasing the weight percentage of $\mathrm{ZrO}_{2}$ can be due to trapping of $\mathrm{ZrO}_{2}$ 


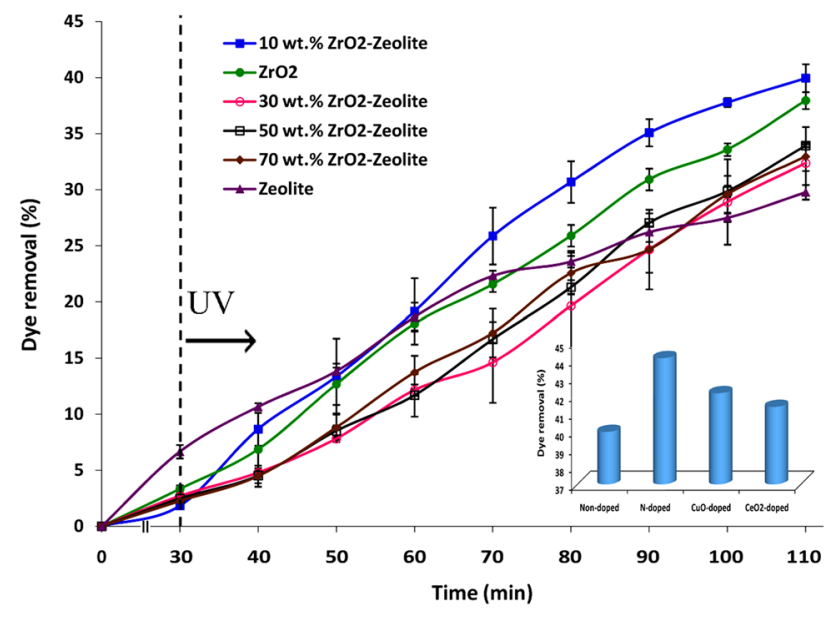

Figure 5. MO photocatalytic degradation by different catalysts (scatter chart), effect of doping a $10 \mathrm{wt} \% \mathrm{ZrO}_{2}$-zeolite nanocatalyst (column chart).

in the pores of the zeolite catalyst, which causes reduction in zeolite adsorption, and $\mathrm{ZrO}_{2}$ itself is not well deposited at the zeolite surfaces. However, addition of $\mathrm{ZrO}_{2}$ to zeolite increases the ability of photo-catalytic and adsorption processes. Therefore, adsorbed pollutants on the surface of the catalyst are more affected by produced hydroxyl radicals and increase the decomposition rate of pollutants $[8,13]$.

\subsection{The doped $\mathrm{ZrO}_{2}-\mathrm{Ze}$ catalyst}

In this work, addition of a promoter to increase the photocatalytic decomposition efficiency was also investigated. The MO photo-catalytic degradation using the optimum catalyst of $10 \mathrm{wt} \% \mathrm{ZrO}_{2}-\mathrm{Ze}$ doped by nitrogen, copper oxide and cerium oxide is presented in figure 5 (column chart). As shown in this column chart, the $\mathrm{N}$-doped $\mathrm{ZrO}_{2}-\mathrm{Ze}$ catalyst has the highest dye removal. The photocatalytic degradation of MO by a doped catalyst with nitrogen, copper oxide and cerium oxide after $80 \mathrm{~min}$ and exposed under UV light increased by about 44,42 and $41 \%$ shows a better performance when compared with $10 \mathrm{wt} \% \mathrm{ZrO}_{2}-\mathrm{Ze}$ catalyst (40\%). This increase may be due to several factors. First, the produced electrons during the irradiation of the energy gap may have migrated to nitrogen; resulting in an increase in the reduction rate of oxygen and subsequently, causes to an increase in the oxidation rate [21]. The energy gap is actually the same wavelength that the semiconductor is excited using radiation. Second, in general, metallation and nitration of catalyst surfaces cause an increase in the electron activation, which is the reason for an increase in photo-catalyst activity [2]. Other researchers have suggested that the compounds of the electrostatic layers produce negative-charge particles, which can be considered as an additional level acceptor between the valence and conductivity bands of semiconductors. Therefore, this level adsorbs the positive-holes to the surface of the catalyst and repulses the electrons towards the bulk. This behaviour is similar to increasing the electron field in photo-catalytic reactions. This behaviour also prevents surface recombination and increases the photo-catalytic degradation rate [22].

\subsection{Photocatalysis investigation using RSM and statistical analysis}

After the determination of the $\mathrm{N}$-doped $10 \mathrm{wt} \% \mathrm{ZrO}_{2}-\mathrm{Ze}$ as an optimum photocatalyst, the MO-photocatalytic removal was also investigated using the RSM. The parameters that are considered in the process are the $\mathrm{pH}$, initial concentration of dye, the amount of loaded catalyst and the power consumption of a UV lamp, each of which is considered in three levels. The Box-Behnken design (BBD) was used as one of the experimental design methods to optimize dye removal. The BBD method uses linear regression for empirical results to determine the coefficients of quadratic polynomial equations [23]. Analysis of photocatalytic dye as a function of $\mathrm{pH}$ values of 3-9, the initial concentration of dye concentration 5-25 $\left(\mathrm{mgl}^{-1}\right)$, the UV lamp power of 4-15 (W) and the concentration of the catalyst in amounts of $0.1-0.4\left(\mathrm{gl}^{-1}\right)$ at the environment temperature was examined. To evaluate the interaction of four-independent parameters on the response function, 27 experiments were designed. The statistical combinations of independent variables with measured values (after 80 min under radiation of UV light) are presented in table 2. Using the obtained results, an empirical relationship between the response and the independent variables, which presented using a quadratic polynomial equation with interactions between independent variables, is obtained. Equation (4) represents the second-order empirical model for dye removing with four dependent variables.

$$
\begin{aligned}
\text { Dye removal }(\%)= & +24.09-3.58 \mathrm{~A}-15.15 \mathrm{~B} \\
& -13.07 \mathrm{C}+17.53 \mathrm{D}+10.06 \mathrm{AD} \\
& -11.53 \mathrm{BC}+14.38 \mathrm{CD}+10.21 \mathrm{~A}^{2} \\
& +6.46 \mathrm{~B}^{2}+38.12 \mathrm{C}^{2}-7.39 \mathrm{D}^{2} .
\end{aligned}
$$

The efficiency of the predicted photo-catalytic conversion is presented using the equation above in the analysis of the variance (ANOVA) table. To interpret the model, tests have been performed to evaluate the efficiency of each model coefficient. The results for the dye removal responses are summarized in the ANOVA table (table 3).

The results show that there is good compatibility between the experimental and predicted values for the photo-catalytic conversion efficiency. The value of the correlation coefficient $R^{2}$ is 0.89030 , which is acceptable; indicating that the $89.03 \%$ of the data variations can be explained by the model. The obtained value of $F$ is equal to 6.67 , which is in agreement with the value of $F$ presented in the statistical tables, and shows that the gained model is suitable. On the other hand, the value of $P$ is equal to 0.0654 for the lack of the fit term which indicates that the ratio of the lack of fit to pure error is not significant and the model is acceptable [1]. Also, the value of obtained $P$ in the analysis of the variance table was 
Table 2. Box-Behnken experiments along with actual values.

\begin{tabular}{|c|c|c|c|c|c|}
\hline Run & A: catalyst loading $\left(\mathrm{g}^{-1}\right)$ & B: dye concentration $\left(\mathrm{mg} \mathrm{l}^{-1}\right)$ & $\mathrm{C}: \mathrm{pH}$ & D: UV lamp power (W) & MO removal $(\%)$ \\
\hline 1 & 0.25 & 5.00 & 7.00 & 15.00 & 35.8 \\
\hline 2 & 0.25 & 15.00 & 7.00 & 8.00 & 22.7 \\
\hline 3 & 0.40 & 15.00 & 9.00 & 8.00 & 8.43 \\
\hline 4 & 0.10 & 15.00 & 7.00 & 4.00 & 21.14 \\
\hline 5 & 0.10 & 25.00 & 7.00 & 8.00 & 27.27 \\
\hline 6 & 0.25 & 5.00 & 3.00 & 8.00 & 82.43 \\
\hline 7 & 0.25 & 15.00 & 9.00 & 4.00 & 3.95 \\
\hline 8 & 0.40 & 15.00 & 7.00 & 15.00 & 46.84 \\
\hline 9 & 0.25 & 5.00 & 7.00 & 4.00 & 5.29 \\
\hline 10 & 0.25 & 25.00 & 3.00 & 8.00 & 79.05 \\
\hline 11 & 0.25 & 15.00 & 3.00 & 15.00 & 78.2 \\
\hline 12 & 0.25 & 25.00 & 7.00 & 4.00 & 2.45 \\
\hline 13 & 0.25 & 15.00 & 7.00 & 8.00 & 19.95 \\
\hline 14 & 0.25 & 15.00 & 9.00 & 15.00 & 77.1 \\
\hline 15 & 0.40 & 5.00 & 7.00 & 8.00 & 61.39 \\
\hline 16 & 0.10 & 15.00 & 3.00 & 8.00 & 91.18 \\
\hline 17 & 0.25 & 25.00 & 7.00 & 15.00 & 19.66 \\
\hline 18 & 0.40 & 25.00 & 7.00 & 8.00 & 5.28 \\
\hline 19 & 0.25 & 25.00 & 9.00 & 8.00 & 4.96 \\
\hline 20 & 0.40 & 15.00 & 7.00 & 4.00 & 3.8 \\
\hline 21 & 0.25 & 15.00 & 3.00 & 4.00 & 53.14 \\
\hline 22 & 0.25 & 5.00 & 9.00 & 8.00 & 39.07 \\
\hline 23 & 0.40 & 15.00 & 3.00 & 8.00 & 80.63 \\
\hline 24 & 0.10 & 5.00 & 7.00 & 8.00 & 84.99 \\
\hline 25 & 0.25 & 15.00 & 7.00 & 8.00 & 13.64 \\
\hline 26 & 0.10 & 15.00 & 9.00 & 8.00 & 18.45 \\
\hline 27 & 0.10 & 15.00 & 7.00 & 15.00 & 28.2 \\
\hline
\end{tabular}

Table 3. Analysis of variance (ANOVA) for fit of decolourization efficiency from BBD.

\begin{tabular}{lccc}
\hline Source of variations & Model & Residuals & Lack of fit \\
\hline Sum of squares & $20,409.80$ & 4170.32 & 4127.17 \\
Degree of freedom & 11 & 15 & 13 \\
Mean square & 1855.44 & 278.02 & 317.47 \\
$F$-value & 6.67 & & 14.71 \\
$P$-value & 0.0005 & & 0.0654 \\
$R$-squared & 0.8903 & & \\
\hline
\end{tabular}

equal to 0.0005 for the proposed model which is valuable. According to the results of the researchers, the level of significance $<0.05$ is assumed to be so small that it can be concluded that there is a significant difference between the methods. To summarize, ANOVA for the quadratic model ( $F=6.67, P=0.0005$ ) shows that the model is acceptable and $<0.05 \%$ probability is due to chance $[1,23]$.

In order to find the maximum area and to investigate the MO removal efficiency, two-dimensional and three-dimensional contour graphs have been used. To study the effect of the amount of the loaded catalyst on the photocatalytic conversion efficiency, the concentration of MO solution $v s$. photocatalyst was investigated in the consumption power of UV lamp $15 \mathrm{~W}$ and $\mathrm{pH}=7$. As shown in figure $6 \mathrm{a}$, the dye removal percentage is increased with increasing in the amount of the loaded catalyst (N-doped $10 \mathrm{wt} \% \mathrm{ZrO}_{2}$-zeolite) and decreasing in the concentration of the dye solution. It can also be seen that in the dye concentration range of $5 \mathrm{mg} \mathrm{l}^{-1}$ and catalyst concentration of 0.1 to $0.4 \mathrm{mgl}^{-1}$, the highest percentage of photo-catalytic removal was obtained which arrived from 59 to $73 \%$. By increasing the photocatalyst concentration, many active sites were produced that cause to increase the removal speed and efficiency. On the other hand, an increase in the photocatalyst concentration causes to increase turbidity and interferes in light passing through the solvent, which cause to reduce the removal rate [1].

Huang and Shu removed the $\mathrm{MO}$ dye using a $\mathrm{TiO}_{2}$-modified platinum photocatalyst on natural zeolite, and investigated the different concentrations of the catalyst from 1.5 to $6 \mathrm{~g} \mathrm{l}^{-1}$. The results showed that by increasing the concentration of the catalyst in a range from 5 up to $3 \mathrm{~g}^{-1}$, the amount of decolourization significantly increased from 59.2 to $90.5 \%$ from MO solution. Then, this intensity is decreased by increasing the catalyst concentration which is due to the light scattering and screening effect [24]. Several studies have reported 
(a)

(c)
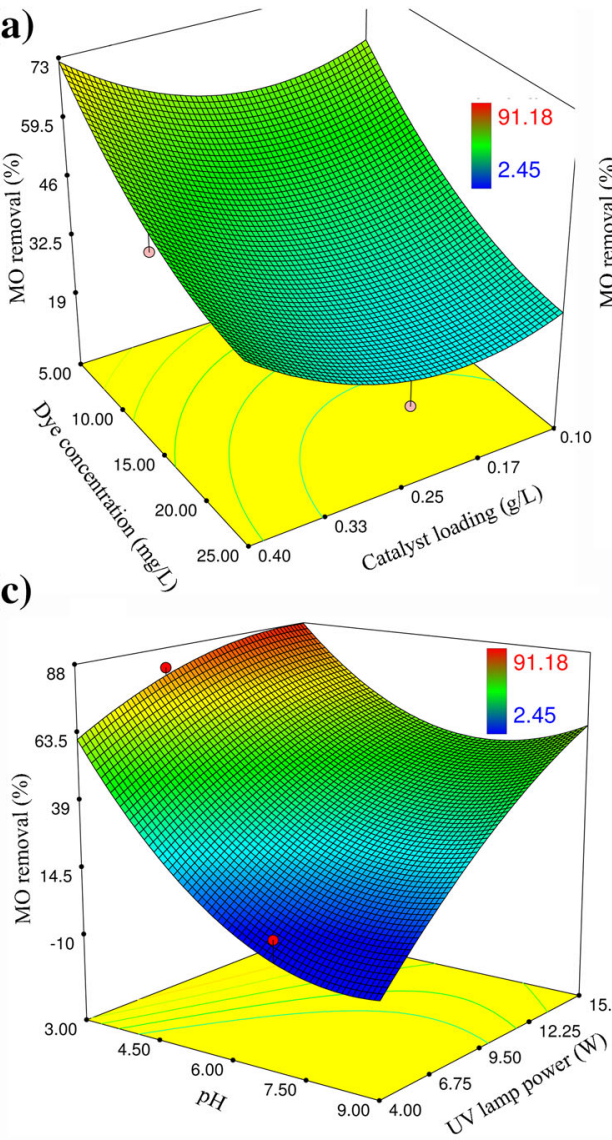

(b)

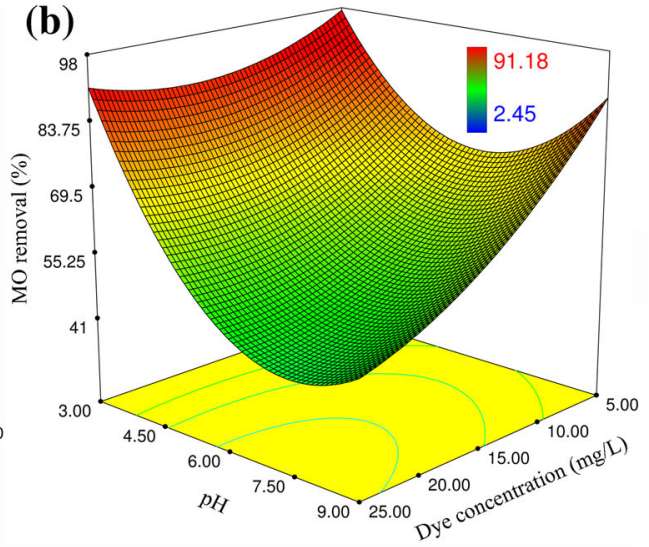

(d)

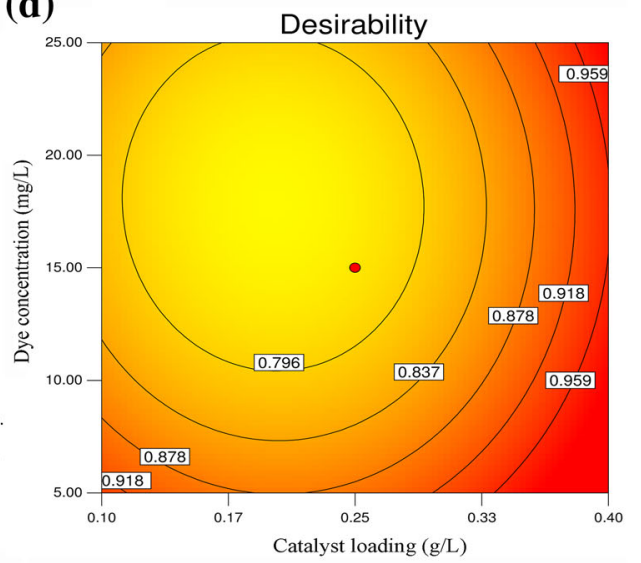

Figure 6. Contour plot, $(\mathbf{a}-\mathbf{c})$ the effect of operational parameters on MO removal efficiency and (d) the percentage of MO removal under optimal conditions.

that the degradation efficiency is reduced with increasing photocatalyst concentrations over the certain limits [2-5,912]. Figure $6 \mathrm{~b}$ shows the effect of the MO dye concentration and the solution $\mathrm{pH}$ on the photocatalytic conversion efficiency at the UV lamp power of $15 \mathrm{~W}$ and the catalyst loading of $0.4 \mathrm{gl}^{-1}$. As is clear that the highest percentage of dye removal has been obtained at $\mathrm{pH} 3$ and a dye concentration of $5 \mathrm{mg} \mathrm{l}^{-1}$. By increasing the concentration of pollutants, the final removal rate of the dye decreases, which indicates a negative effect of increasing concentration of the reaction. At high dye concentrations, most active sites may be coated with dye ions. This may be a reason to reduce the production of $\mathrm{OH}$ radicals on the catalytic surface and will be presented with lower efficiency along with the reduced efficiency of degradation [25]. Barakat in his study stated that the reason for reduction in the percentage of dye at higher concentrations is due to the turbidity and also adsorption on the catalyst surface, followed by the decreasing of active sites [20]. Figure 6c shows three-dimensional contour graph for the photo-catalytic dye removal efficiency as a function of the solution $\mathrm{pH}$ and the power consumption of the UV lamp at constant concentration levels of dye solution $\left(15 \mathrm{mg}^{-1}\right)$ and the amount of loaded catalyst $\left(0.4 \mathrm{gl}^{-1}\right)$. It is obvious that the photo-catalytic removal also increases with increasing in the lamp power consumption and decreasing in the $\mathrm{pH}$. The highest dye removal achieves at UV lamp power $=15 \mathrm{~W}$ and $\mathrm{pH}=3$. The higher UV power provides greater energy for the photocatalyst particles to produce the electron-hole pairs, hence, the removal rate increases at higher powers of the UV lamp.

The environmental $\mathrm{pH}$ has complex effects on the reaction rate of photocatalytic oxidation. It depends on the adsorption of the pollutant on the catalyst surface, and its degradation rate near the zero point charge of the catalyst. Therefore, the optimum $\mathrm{pH}$ of the environment varies depending on the nature of each pollutant $[1,21,22]$. This index significantly changes the particle surface charge, the oxidation potential and the position of energy bands. Muruganandham et al [26] showed that the effect of $\mathrm{pH}$ is related to the potential properties of the photocatalytic surface and can be explained based on the potential of zero point (PZC). The pH of PZC for $\mathrm{ZrO}_{2}$ and zeolite- $\mathrm{NaX}$ is 6.7 and 4.7, respectively. At $\mathrm{pH}$ values lower than 6.7 and 4.7, or in other words, in the acidic $\mathrm{pH}$, the catalytic surface receives positive charge, which results in photocatalyst adsorption of anionic and repulsion of cationic compounds. Conversely, at $\mathrm{pH}$ values higher than 6.7 , the 
catalyst surface receives a negative charge, which results in cationic adsorption and anionic compounds being repulsed. Muruganandham et al [26] found that by increasing the $\mathrm{pH}$ from 1 to 9 , the decolourization rate for 14-orange was in the range of 15.16 to $87.28 \%$ after $80 \mathrm{~min}$, however, the faster dye removal observes in alkaline $\mathrm{pH}$. In contrast, the study of some azo-dyes showed different results [27]. For example, 17-yellow acid shows the highest degradation at $\mathrm{pH} 3$, and for orange II and Amiddoblack-10B the highest degradation is reported at $\mathrm{pH} 9$ [28]. Zhu et al [29], in their study on MO concluded that the highest degree of decolourization that resulted in the removal of $97 \%$ of the colour was observed at $\mathrm{pH} 2$, which attributed to the electrostatic absorbance between the positive surface of the catalyst and the MO anion. The reason for the higher process efficiency under acidic $\mathrm{pH}$ conditions is that in acidic environments, $\mathrm{H}^{+}$ions are absorbed on the surface of $\mathrm{FiO}_{2}$. In this case, the generated electrons can increase the number of negative-charge sites using $\mathrm{H}^{+}$ ions. The number of negative-charge sites on the catalyst surface cannot be effective in the dye removal. Thus, an increase in $\mathrm{pH}$ causes a decrease in the photocatalyst ability in the removal of dye. The MO dye is also anionic and hence, in acidic $\mathrm{pH}$, it is better adsorbed on the photocatalyst particle surface with positive charge, and the removal process in acid $\mathrm{pH}$ is performed much more effectively than alkaline $\mathrm{pH}$.

In order to select the optimum conditions, in addition to achieving the highest removal percentage in the highest pollutant concentration, lower consumption of the catalyst is considered to reduce the costs. Two-dimensional contour graph in figure $6 \mathrm{~d}$ shows the performance removal contour for MO-dye and gained optimal level based on the loaded catalyst $\left(\mathrm{g}^{-1}\right)$, initial concentration of dye $\left(\mathrm{mg}^{-1}\right)$, UV lamp consumption power of $15 \mathrm{~W}$ and $\mathrm{pH}=3$. As can be seen, one of the optimal points with the highest catalytic decomposition can be determined at an initial concentration of $5 \mathrm{ppm}, \mathrm{pH} 3$, loading catalyst of $0.4 \mathrm{~g} \mathrm{l}^{-1}$ and the lamp power of $15 \mathrm{~W}$.

\subsection{Kinetic study of photocatalytic removal reaction}

The reaction kinetics for heterogeneous catalytic systems are described by kinetic models in which reactions begin with adsorption of matter on the solid phase. In this model, the adsorption on the catalyst is assumed to be an elementary reaction [30].

One of these models is the Langmuir-Hinshelwood model, in which the material is absorbed on the catalyst and then the chemical reaction takes place at the catalyst surface. The model is as follows:

$$
-\frac{\mathrm{d} C}{\mathrm{~d} t}=\frac{k_{\mathrm{r}} K_{\mathrm{e}} C}{1+K_{\mathrm{e}} C}
$$

where $k_{\mathrm{r}}$ and $K_{\mathrm{e}}$ are the kinetic constant of the LangmuirHinshelwood and the Langmuir kinetic constant, respectively.
With assuming first-order kinetics for the case with low concentration of pollutants, the above relationship will represent the kinetic of the first-order reaction. Integrating equation (5), with initial condition of $C=C_{0}$ at $t=0$, gives:

$$
\ln \left(\frac{C}{C_{0}}\right)=-k_{\text {app }} t
$$

where $k_{\text {app }}$ is a superficial speed of the first-order reaction. The above pseudo first-order kinetic has been reported in many photocatalytic studies [30-32]. The rate constant was estimated from the slope of $\ln \left(C / C_{0}\right) v s$. time, plotted under optimized conditions. The obtained $k_{\text {app }}=0.031 \mathrm{~min}^{-1}$ from this investigation shows the high-constant speed of the reaction under the optimized conditions, which is also proving the efficiency of the used optimization methods of the reaction.

\section{Conclusions}

In this study, the efficiency of loaded $\mathrm{ZrO}_{2}$ nanoparticles on the zeolite- $\mathrm{NaX}$ as a photocatalyst exposed under UV radiation for degradation of MO-dye from water was investigated. Complete removal of $\mathrm{MO}$ was achieved using $\mathrm{N}$-doped $10 \mathrm{wt} \% \mathrm{ZrO}_{2}-$ zeolite. The effect of the initial concentration of the contaminants on the photo-catalytic degradation showed that by increasing the initial concentration of MO from 5 to $25 \mathrm{mgl}^{-1}$, the photo-catalytic degradation rate decreases. This is due to the high absorption of UV light at very high concentrations, and as a result, the solution acts as an effective internal filter. Under these conditions, a smaller portion of the photons reaches to the semiconductor, and subsequently the production efficiency of hydroxyl radicals and the rate of degradation decreases. It was also found that increasing the concentration of the loaded nanocatalyst in the dye solution increases the amount of dye degradation. According to the results, it was found that the percentage of dye degradation with the power consumption of the UV lamp had a linear relation. Increasing the power of the UV lamp increases the energy of nanoparticles in order to produce an electron-hole pair, thus the removal rate raised at higher power of UV lamps. The results also showed that the $\mathrm{pH}$ plays an important role in the removal rate of $\mathrm{MO}$ contamination, so that the photocatalytic degradation of this anionic pollutant in acidic $\mathrm{pH}$ has a much higher efficiency than in a neutral and alkaline $\mathrm{pHs}$. The physical properties of the synthesized nanoparticles were also determined using XRD, FTIR, SEM and BET. The SEM image showed that $\mathrm{ZrO}_{2}$ nanoparticles have a spherical structure and uniform with size distribution approximately equal to $40 \mathrm{~nm}$, and that $\mathrm{ZrO}_{2}$ particles are uniformly dispersed on a cubic surface of zeolite. In general, the results of this study showed that the nanophotocatalyst of N-doped $10 \mathrm{wt} \% \mathrm{ZrO}_{2}$-zeolite has a high efficiency for the degradation of anionic MO-dyes and can be used as an efficient option 
for purifying coloured dye and destroying environmental pollutants.

\section{Acknowledgements}

MM thanks the University of Ilam, for the award research fellowship.

\section{References}

[1] Mansouri M, Tanzifi M, Lotfi H and Nademi M 2017 St. Cerc. St. CICBIA 18153

[2] Alalm M G, Ookawara S, Fukushi D, Sato A and Tawfi A 2016 J. Hazard. Mater. 302225

[3] Ahmad T, Shahazad M and Phul R 2017 Mater. Sci. Eng. Int. J. 1100

[4] Mahadwad O K, Parikh P A, Jasra R V and Patil C 2011 Bull. Mater. Sci. 34551

[5] Khatamian M, Hashemian S and Sabaee S 2010 Mater. Sci. Semicond. Process. 13156

[6] Ökte A N and Yilmaz Ö 2008 Appl. Catal. B 8592

[7] Bhattacharjee S, Sarkar S H, Raybarman U and Panja J 2016 Int. J. Innov. Res. Sci. Technol. 2284

[8] Panpa W, Sujaridworakun P and Jinawath S 2008 Appl. Catal. B 80271

[9] Zhao J, Wang X, Zhang L, Hou X, Li Y and Tang C $2011 \mathrm{~J}$. Hazard. Mater. 188231

[10] Ismail S, Ahmad Z A, Berenov A and Lockman Z 2011 Corros. Sci. 531156

[11] Basahel S N, Ali T T, Mokhtar M and Narasimharao K 2015 Nanoscale Res. Lett. 1073

[12] Yoa S, Jia X, Jiao L, Zhu C and Shi Z 2012 Indian J. Chem. 51A 1049
[13] Mzoughi M, Anku W W, Oppong S O B, Shukla S K, Agorku E S and Govender P P 2016 Res. Artic. Adv. Mater. Lett. 7946

[14] Amaladhas P T and Thavamani S S 2013 Adv. Mater. Lett. 4 688

[15] Ivanova T, Harizanova A, Koutzarova T and Vertruyen B 2010 Cryst. Res. Technol. 451154

[16] Hao Y, Li J, Yang X, Wang X and Lu L 2004 Mater. Sci. Eng. A 367243

[17] Manivannan M and Rajendran S 2011 Int. J. Eng. Sci. Technol. 38048

[18] Devi L G and Rajashekhar K E 2011 J. Mol. Catal. A: Chem. 33465

[19] Xin W, Zhu D, Liu G, Hua Y and Zhou W 2012 Int. J. Photoenergy 20121

[20] Barakat M 2011 J. Hydro. Environ. Res. 5137

[21] Zhao S, Ramakrishnan G, Shen P, Su D and Orlov A 2013 Chem. Eng. J. 217266

[22] Chakrabarti S and Dutta B K 2004 J. Hazard. Mater. 112269

[23] Mansouri M, Atashi H, Khalilipour M M, Setareshenas N and Shahraki F 2013 J. Korean Chem. Soc. 57769

[24] Huang C R and Shu H Y 1995 J. Hazard. Mater. 4147

[25] Espino-Estévez M R, Fernández-Rodríguez C, González-Díaz O M, Araña J, Espinós J P, Ortega-Méndez J A et al 2016 Chem. Eng. J. 29882

[26] Muruganandham M, Shobana N and Swaminathan M $2006 \mathrm{~J}$. Mol. Catal. A: Chem. 246154

[27] Sakthivel S, Neppolian B, Murugesan L and Venkatakri S H 2003 Sol. Energy Mater. Sol. Cells. 7765

[28] Qamar M, Saquib M and Muneer M 2005 Dyes Pigm. 651

[29] Zhu H, Jiang R, Fu Y, Guan Y, Xiaob L, Yao J et al 2012 Desalination 28641

[30] Nodehi A, Atashi H and Mansouri M 2019 J. Dispersion Sci. Technol. 40766

[31] Arabi A, Fazli M and Ehsani M H 2018 Bull. Mater. Sci. 4177

[32] Ahmed T, Phul R, Alam P, Lone I H, Shahazad M, Ahmed J et al 2017 RSC Adv. 727549 